\title{
Firm Environmental Innovation Behavior Under Heterogeneous Demand: An Adaptive, Agent-Based Modeling Approach
}

\author{
Aiwu Zhao a, ${ }^{\mathrm{a}}$, Jianguo $\mathrm{Du}^{\mathrm{a}}$ and Hongjun Guan ${ }^{\mathrm{b}}$ \\ ${ }^{a}$ School of Management, Jiangsu University, Zhenjiang Jiangsu, 212013, China; ${ }^{b}$ School of Management Science and \\ Engineering, Shandong University of Finance and Economics, Jinan Shandong, 250014, China
}

\begin{abstract}
Because of the complexity and diversity of human behavior, social systems are unpredictable and difficult to quantify. With the development of computer technology, scholars have begun to construct artificial systems to simulate real social systems in order to explore the trajectory of social phenomena. In this paper, we combined complex system modeling theory with a computational experimental method to construct an adaptive, multi-agent-based system. For this purpose, we constructed heterogeneous firm and consumer agents. Each agent has its own properties, behavioral rules, and interaction rules, which can be adjusted according to its experiences. Our model is based on an abstraction of the real world. We first applied the model to simulate consumers' product selection process and firms' product innovation decision-making process. Then, we analyzed the internal mechanisms affecting consumers' green demand and firms' environmental behavior. The experimental results revealed that consumer preferences for products with high environmental performance encourage firms to pursue environmental innovation. When green demand among consumers is sufficiently high, firms can obtain high economic profits when they engage in environmental innovation, whereas when green demand among consumers is low, the government should intervene with mechanisms such as subsidies or incentives to encourage firms to engage in environmental innovation. However, as a rapid increase in green demand would quickly lead to a market monopoly, firms should respond to changes in the market in a timely manner to avoid being eliminated from the market.
\end{abstract}

Keywords: Agent-based modeling, computational experiment, environmental innovation behavior, green demand, heterogeneous agent.

\section{INTRODUCTION}

Mathematical methods are commonly used in natural science. However, because of the complexity of social systems, mathematical methods have rarely been successfully used in social science. When we study a social phenomenon, we typically adopt empirical methods $[1,2]$ : we combine sample research with quantitative or qualitative analysis; then, we summarize and deduce our results according to the theories and experiences of related disciplines. Nevertheless, because of differences between environments and limitations in samples, the conclusions may be one sided or even incorrect.

It has become a hot research topic for scientists to search for new scientific research paradigms in social science, as in natural science. This trend led to the development of the discipline of computational social science [3]. Within this discipline, social scientific problems are explored by using computer technology based on traditional humanities and social science theory. Models are developed based on attributes, rules are abstracted from the real world, and computers are used to construct the artificial simulation platform. By adjusting related parameters, we can simulate the detailed steps of an entire process under different scenarios to reveal

the internal mechanisms and trends of a phenomenon. The application of computational methods to social science not only offers the potential to improve the depth and precision of research on specific issues but also can promote the "big science" themes of "qualitative and quantitative [research], computational experiments, linkage of artificial system and real world, [and] combination and integration".

Currently, computational experiments are widely used in many social science fields, such as financial markets; environmental governance; economic development and social management; industrial agglomeration; technological innovation; public safety; public opinion, coordination, and management; supply chain management; major projects; infectious diseases mechanisms; public health management; and language and history evolution. Many such studies have achieved substantial success. For example, Authur and other research fellows at the Santa Fe Institute used an agent-based computer model to study capital markets. For this purpose, they constructed an artificial stock market, which marked the birth of experimental finance. This artificial stock market allows experimenters to independently design the trading environment, trading bargainers, trading objects, and trading strategies to reveal the internal mechanisms of a capital market. Furthermore, by combining methods from computational social science with methods from economics, Kenett et al. developed an approach to effectively locate crisis events within the massive amount of data generated on Twitter [4]. 
With the rapid development of industry, increasingly severe pollution problems have emerged. Moreover, resources and environmental problems have become impediments to the sustainable development of economies. The alleviation of the contradiction between economic growth and high-energy consumption or environmental degradation has thus become an important challenge worldwide [5,6]. Firms' clean production processes and environmental innovation behavior are generally recognized to be the key to sustainable development. Accordingly, we hope to encourage more firms to voluntarily adopt environmental innovation technologies and to develop environmentally innovative products. However, because environmental behavior represents an externality, firms' environmental decision-making mechanisms are highly complex and are influenced by numerous factors. In this paper, we constructed a dynamic simulation model of firms' innovation behavior based on empirical data derived from investigations and studies. We then conducted a computational experiment to dynamically simulate firms' innovation decision-making process under different scenarios. We focus on revealing the interaction mechanism between internal and external factors that affect firms' environmental innovation decisions. Finally, we propose environmental policy recommendations based on our experimental results.

\section{RELATED WORKD}

Many countries have developed legal frameworks to reduce the impact of industrial development on the environment [7]. Within these legal frameworks, government regulations, a traditional approach to pollution control, have played an important role in encouraging firms to reduce their emissions and to implement clean production technology to protect the environment $[8,9]$. However, research has shown that local governments often pursuit economic growth without considering the environment. Furthermore, environmental law is not strictly implemented, and meeting inspections has become a mere formality for firms. These circumstances have weakened the enforcement of environmental policies and regulations. Meanwhile, investment in clean production and environmental innovation is high, yet the lack of economic incentive policy has hindered the development of cleaner production [10-12]. Fortunately, market and community pressure has become a crucial driving force to supplement government regulations [13]. Increasing numbers of firms have recognized that engaging in environmentally friendly behavior is important for improving their competitiveness [14]. These firms have thus begun to consciously adopt environmental behavior. As a result, increasingly more researchers have begun to study the game theoretic rules and passive feedback of firms' environmental behavior under a demand-oriented market. Indeed, the drivers of firms' environmental behavior have become a hotter topic than environmental regulations [15-17].

Monroe found that consumer perceived value leads to heterogeneous demand [18]; that is, consumers have heterogeneous preferences for products. Thus, regarding concern for the environment, an individual preference for environmental protection leads to green demand. Green consumers increasingly emphasize ecological protection issues. Hence, if manufacturers ignore the environmental characteristics of their products, green consumers will reject these products.
As raw material prices on the global market have become nearly uniform, the potential for cost competition is increasingly limited. Firm managers have therefore begun to devote greater attention to market feedback. Wen proposed that consumer green demand has become a powerful driving force in promoting green innovations [19], as consumer purchasing behavior can significantly influence the environmental behavior of firms and their supply chain members. Moreover, consumers' green purchasing behavior is closely related to firms' net income. Therefore, firms generally alter their industrial and market orientations to create an advantage by developing technology, such as product innovations. Bekiroglu investigated the construction industry in Turkey based on empirical data and found that firms compete on price, product quality, and environmental sustainability to gain market share through product innovation [20]. His research also revealed that the product innovation trajectory depends on the preferences of heterogeneous consumers regarding products' price, quality, or environment performance. In other words, consumer preferences determine whether firms adopt new, cleaner production technology and more environmentally friendly technology. To study the evolution of the automobile industry in the United States [21], Paul simulated the relationship between consumer preferences and environmental pollution during different periods by using a technology competition model. His study revealed the importance of heterogeneous preferences in firms' new technology development and confirmed that the adoption, development, and diffusion of new technologies are endogenous. George studied the impact of firms' environmental management and environmental policy on stock value from a capital market perspective [22]. The study showed that firms increasingly improve their image by developing environmentally friendly products and services. Further, firms can reduce their business risks by improving their environmental management and environmental performance.

Many traditional research perspectives nevertheless continue to hold firms' environmental performance is negatively associated with their economic performance [23]. Furthermore, the innovation processes involved in developing clean production technology are subject to the uncertainties of the business cycle. The return cycle for investments in innovation is long and uncertain, and market volatility and regulatory change may affect the technology development process and generate risks. Moreover, production costs for green products are typically much higher than those for conventional products; thus, prices are generally higher for green products. However, customers' green preferences are often inconsistent with their actual purchasing behavior-they may have a positive perception of green products, but they do not wish to pay more for these products [24]. Therefore, adapting to actual market demand is a challenge for firms. Lin investigated the motorcycle industry in Vietnam and found that market demand and green product innovation are positively correlated with firms' image [25]. As consumers become increasingly aware of environmental protection, green innovation firms can eventually achieve a win-win result of being "green" and "competitive". Eva calculated and analyzed the environmental and economic performance data of 1176 firms from 2004 to 2008 [26]. The results revealed that the short-term costs of environment innovation 


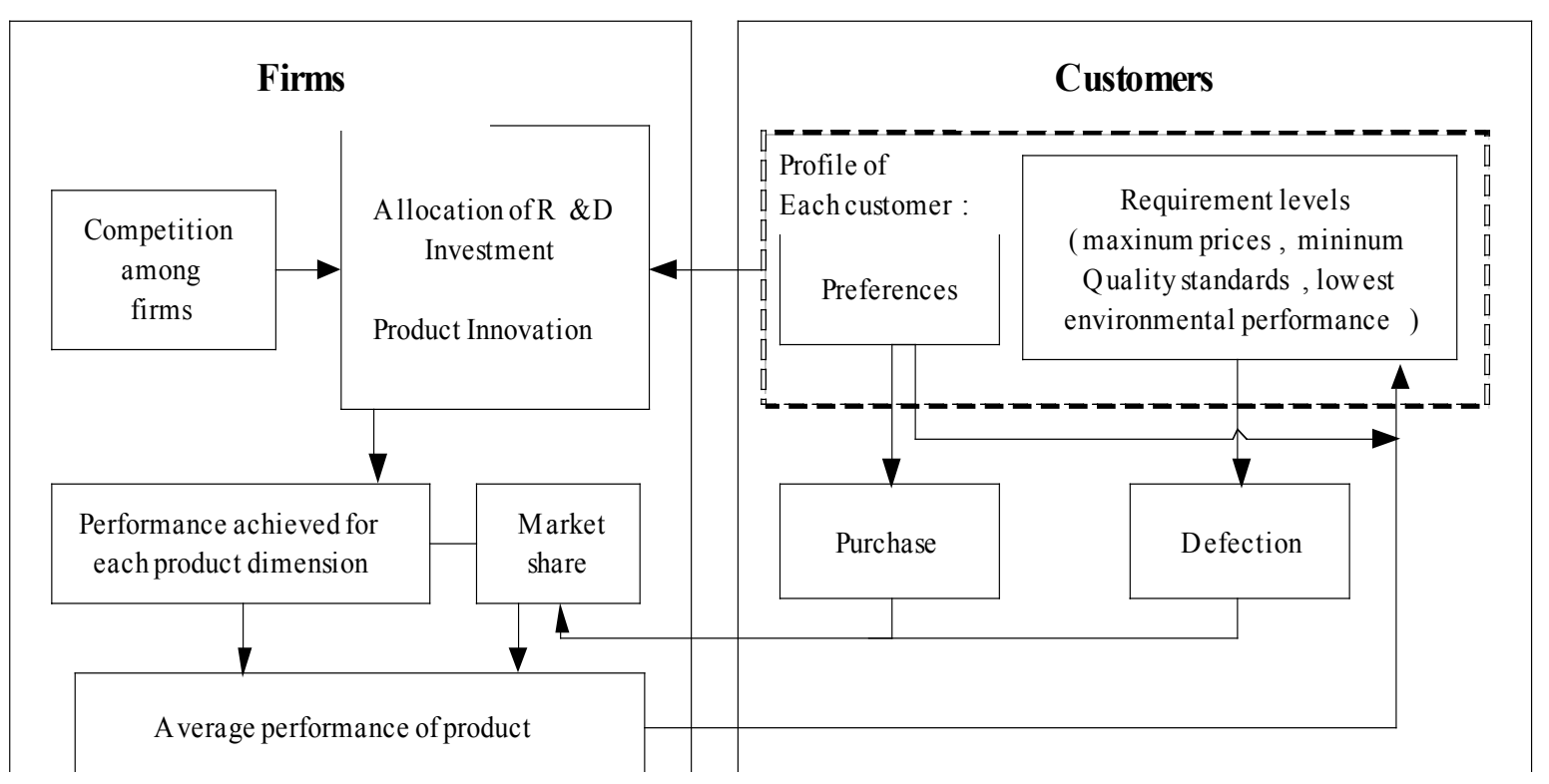

Fig. (1). Interaction between customers and firms.

might initially reduce firms' economic performance but that firms pursuing environmental innovation would increase both their environmental and economic performance in the long run.

Although many scholars have shown that green demand has a significant effect on firms' environmental management and although these studies have provided valuable suggestions to encourage firms to protect the environment, the approaches adopted in these studies remain narrow, and their views are rather limited [27]. How does environmental innovation affect firms' economic performance in different green demand contexts? How do firms respond to consumers' heterogeneous demand? How can one open this "black box" to explore the intrinsic mechanism underlying it? These issues have not been fully explained in the literature. Ilker noted that the green market remains very young, that manufacturers and governments promise improvements in environmental performance, and that customers support green products, all which are crucial for the further protection of our environment [28]. Therefore, we must explore the internal mechanisms underlying firms' environmental innovation behavior and the mechanisms explaining the interactions among complex external factors, determine the trajectory of such innovation in different contexts, and encourage firms to implement green and sustainable development strategies.

\section{MODEL DEVELOPMENT}

\subsection{Assumptions and Notation}

Our model primarily comprises two types of agents: firms and consumers. Both types of agents are able to learn and adapt, to make decisions in response to a changing environment, interactions, and attributes, and to adjust their properties according to their previous experiences and accessed information. Consumers make purchasing decisions according to their preferences, while firms decide whether to pursue innovation according to market demand. Moreover, through technological innovation, firms improve the characteristics of their products to satisfy consumers and to gain market share. Further, technological innovation influences consumers' preferences and the overall level of demand in the market. The interaction between consumers and firms is depicted in Fig. (1).

The main assumptions and notations of the model are as follows:

(1) $n$ denotes the number of firms, and $m$ denotes the number of customers. All firms in our model produce similar products. There are three dimensions of product characteristics: environmental performance, price, and quality. The firm characteristics are financial condition (associated with the loss threshold), innovative attitude (i.e., positive, prudent, or conservative), and innovation preferences (i.e., environmental, economic, or market demand). If a firm's accumulated losses exceed its loss threshold, the firm will be eliminated from the artificial market.

(2) According to their sensitivity to a product's price, quality, and environmental performance, consumers are divided into three categories, representing $a_{1}, a_{2}$, and $\left(1-a_{1}-a_{2}\right)$ of the total number of consumers. The first type of consumers constitute practical individuals, who are highly sensitive to quality, moderately sensitive to price, and insensitive to environmental performance. The second type of consumers constitute economic consumers, who are sensitive to price and less sensitive to quality and environmental performance. The third type of consumers constitute green consumers, who are highly sensitive to the environmental performance of products and relatively insensitive to price and quality. Each type of consumer has a different level of demand for the three product dimensions. Even within a given type, each consumer has his own specific demand for each dimension. Consumers make their purchasing decisions according to their preferences.

(3) We assume that production efficiency does not exhibit increasing returns to scale and that costs can only be reduced by improving production efficiency through techno- 
logical innovation. Thus, a product's price is based on the cost of production, where the pricing formula is $p=c(1+\mu), p$ is the product's price, $\mu$ is producers' satisfactory profit level (considering their limited rationality), and $c$ denotes production cost. Furthermore, we assume that the satisfactory profit levels are equal for all producers. The pricing formula suggests that production efficiency reflects product prices.

(4) By expanding their market share, producers gain additional economic benefits. To obtain a competitive advantage by meeting the requirements of more consumers, firms make decisions regarding how and when to adopt technical innovation according to their characteristics and market feedback. Innovations designed to improve production efficiency (reduce prices) or product quality are classified as traditional innovations, and other innovations focusing on developing green products or improving environmental performance are classified as environmental innovations. The two types of technical innovations increase product costs while improving product performance. Further, environmentally friendly raw materials are generally used to improve products' environmental performance, which will increase the product price and, occasionally, even lower the product quality.

(5) We assume that the products are easily consumed and that consumers must select one of the firms' products in each transaction. If no product satisfies the consumer's preferences, the consumer will choose the same firm's product as in a prior transaction according to the principle of path dependence.

\subsection{Behavioral Rules of the Agents}

We define the behavioral rules of our agents with respect to the above assumptions.

\subsubsection{Behavioral Rules of Consumer Agents}

Consumer agents select products from different firms according to principle of path dependence and their preferences. Further, their preferences are affected by the overall level of market demand. Time is discrete, and the generic time-step is denoted $t=1,2, \ldots, T$, where $t=0$ represents the initial state, $t=T$ represents the last time-step, and $x_{i, t}^{h}(i=1, \ldots, m, h=1,2,3)$ represents the preferences concerning the product price, quality, and environmental performance of agent $i$ at time-step $t$. Then, we obtain:

$\begin{cases}x_{i, t}^{h}=x_{i, t-1}^{h}-\inf _{i} \times \max \left\{\left(x_{i, t-1}^{h}-x_{a, t-1}^{h}\right), 0\right\} & h=1 \\ x_{i, t}^{h}=x_{i, t-1}^{h}+\inf _{i} \times \max \left\{\left(x_{a, t-1}^{h}-x_{i, t-1}^{h}\right), 0\right\} & h=2,3\end{cases}$

In formula (1), $\inf _{i}$ represents the degree of sensitivity of agent $i$, which is affected by the overall level of market demand but reflects individual differences. $x_{a, t-1}^{h}$ represents the overall demand level according to the product price, quality, and environmental performance in the prior time-step, $x_{a, t-1}^{h}=\sum_{m} x_{i, t-1}^{h} / m$.
According to assumption (5), each consumer selects one product from a certain firm at each time-step. First, the consumer evaluates the product attributes of the original producer; if its three dimensions all conform to the consumer's preference threshold value (i.e., the price is lower than $x_{i, t}^{1}$, the quality is higher than $x_{i, t}^{2}$, and the environmental performance is higher than $x_{i, t}^{3}$ ), the consumer will select his original producer; otherwise, the consumer will search for a new firm with a product that could satisfy his preferences. If a new firm exists, the consumer will select the new firm instead of the original firm; otherwise, he will maintain his original selection but adjust his preferences as follows:

$$
\begin{cases}x_{i, t}^{h}=x_{i, t-1}^{h}+\varepsilon^{h} & h=1 \\ x_{i, t}^{h}=x_{i, t-1}^{h}-\varepsilon^{h} & h=2,3\end{cases}
$$

$\varepsilon^{h}(h=1,2,3)$ represents a consumer agent's adjustment value of his product price, quality, or environmental performance preference, respectively, $\varepsilon^{h}>0$.

\subsubsection{Behavioral Rules of Firm Agents}

To increase their market share in the presence of fierce competition, firms must improve their product performance through technical innovation. However, innovation is always accompanied by investment and risk. The decision whether to pursue technical innovation depends on the level of perceived consumer demand $R D_{j, t}$, firms' sensitivity to changes in market demand $S E N S_{j}$, firms' probability of innovation $P R O B_{j}$ (a firm property determined by the firm's innovation attitude), the investment required to develop a technological innovation, and so forth. The perceived level of consumer demand $R D_{j, t}$ is determined by the number of unsatisfied consumers in the total of all historical original or potential consumers who selected firm agent $j$, defined as follows:

$$
\begin{aligned}
& R D_{j, t}=R D_{j, t-1}+\operatorname{sens}_{j} \times N_{j, t-1} /\left(N_{j, t-1}+P_{j, t-1}\right)+ \\
& \operatorname{sens}_{j} \times O_{j, t-1} /\left(N_{j, t-1}+P_{j, t-1}\right)
\end{aligned}
$$

$N_{j, t-1}, P_{j, t-1}$, and $O_{j, t-1}$ refer to the number of unsatisfied consumer agents selecting firm agent $j$ in a prior time-step, the number of satisfied consumer agents, and the number of consumer agents lost owing to dissatisfaction, respectively. $\operatorname{sens} 1_{j}$ and $\operatorname{sens} 2_{j}$ represent the sensitivity level of firm agent $j$ to consumer dissatisfaction. Technical innovation requires additional investment, and investment is assumed to be divided over the following $w$ time-steps; that is, if the innovation process began in time-step $t$, the cost would increase by inv/w in the $t+1, \ldots t+w$ time-steps, and no innovation process would be conducted in these time-steps. 
First, a firm agent calculates its demand feedback level $R D_{j, t}$; if $R D_{j, t}$ exceeds its thre shold sensitivity $S E N S_{j}$ and if no additional costs are incurred during this time-step, the decision whether to pursue technical innovation is determined by the firm's probability of innovation: $A C T_{j, t}=\left(\operatorname{If}\left(\operatorname{PROB}_{j}>\operatorname{Random}(0,1)\right)\right.$, true, false $)$. If $A C T_{j, t}$ is true, the firm agent will decide to pursue technical innovation, and it will consider such innovation relative to the degree of dissatisfaction associated with the three dimensions of its product.

$$
\text { RDindex }_{j, t}^{h}=(1-\alpha) \text { RDindex }_{j, t-1}^{h}+\alpha \times\left(N e_{j, t-1}^{h} / N_{j, t-1}\right)
$$

RDindex $_{j, t}^{h}$ is the degree of dissatisfaction with product dimension $h$ of firm agent $j, N e_{j, t-1}^{h}$ is the number of consumer agents whose preference threshold value of dimension $h$ was not satisfied in the prior time-step ( $h=1,2,3$, corresponding to the three dimensions), and $\alpha$ is the information increment coefficient. If a firm's innovation preference type is environmental protection or if $R$ Dindex $_{j, t}^{3}$ is the maximum value and the firm's preference type is demand oriented, the firm agent will pursue environmental innovation. We assume that this type of innovation will lead to greater environmental performance, a higher price, and lower product quality.

$$
\left\{\begin{array}{l}
y_{j, t}^{1}=y_{j, t-1}^{1}+m_{-} \text {back }^{1} \times \operatorname{random}(0,1) \\
y_{j, t}^{2}=y_{j, t-1}^{2}-m_{-} \text {back }^{2} \times \operatorname{random}(0,1) \\
y_{j, t}^{3}=y_{j, t-1}^{3}+m_{-} \operatorname{step}^{3} \times \operatorname{random}(0,1)
\end{array}\right.
$$

$y_{j, t}^{h}$ represents one of the three dimensions of agent $j$ 's performance, $m_{-} b a c k^{h}$ is the reference step value of a price increase or quality decrease, and $m_{-}$step $^{3}$ is the reference increasing step value of environmental performance. Because of the influence of uncertain internal and external factors, the actual changes in product performances are uncertain, represented by random $(0,1)$.

Otherwise, the firm agent will pursue traditional technical innovation, which will result in improved performance in both price and quality. The changing ratios of the two dimensions are as follows:

$\delta_{j, t}^{h}=$ RDindex $_{j, t}^{h} / \sum_{h}$ RDindex $_{j, t}^{h} h=1,2$

The adjusted performance of an innovative product is:

$\left\{\begin{array}{l}y_{j, t}^{1}=y_{j, t-1}^{1}-\delta_{j, t}^{1} \times m_{-} \operatorname{step}^{1} \times \operatorname{random}(0,1) \\ y_{j, t}^{2}=y_{j, t-1}^{2}+\delta_{j, t}^{2} \times m_{-} \operatorname{step}^{2} \times \operatorname{random}(0,1)\end{array}\right.$

If a firm's total sales revenues are less than its total costs and if the negative balance exceeds its loss threshold, the firm agent will withdraw from the market.

\subsection{Model Design}

By defining the above assumptions and behavioral rules, we have mapped the complex production decision process involving firms and individual consumers to multiple agents. Each agent has a unique identifying number. Moreover, we have mapped the characteristics and behavior of firms and consumers to the properties and rules for agents. A consumer agent selects a certain firm's product according to his own preferences, while a firm agent pursues technical innovation to improve the performance of its product to satisfy the requirements of consumer agents. Moreover, consumers' preferences are adjusted according to products' actual market performance and are influenced by the overall level of market demand. By competing on product performance, firms constantly satisfy consumers' demands to compete for market share. Further, agents recall their previous experiences, continuously learn, and self-adapt during the interactions in a dynamic process of evolution. By observing and analyzing the behavior and decision-making rules of each agent in each time-step, we can simulate the transaction process of firms and consumers, observe the technical innovation trajectory at the micro level, and analyze the mechanism underlying the evolution of technical innovation at the macro level. The operational flow chart of the model is depicted in Fig. (2).

At the beginning of each transaction, we sort the consumer agents randomly, visit each of them individually to finish the product selection procedure according to scheduled rules, and renew the information of the consumer agents and the related firm agent. Then, we sort the firm agents randomly, check the status of each firm agent, make decisions whether to pursue technical innovation according to the market demand, and save the transaction and innovation information to a database. The experiment is terminated once the timeframe boundary is reached.

\section{EXPERIMENT AND ANALYSIS OF RESULTS}

The total number of combinations of firms' innovation attitudes, innovation preferences, and financial situations is 27. To include all combinations, let $\mathrm{m}=27$, referring to 27 types of property combinations, and let $n=2700$, referring to the total number of 2700 consumers in our artificial market.

According to our previous assumptions, the proportion of green customers can reflect changes in green demand. We consider three scenarios in the experiments. The proportions of green consumers in these scenarios are $10 \%, 30 \%$, and $60 \%$, while practical consumers and economic consumers are present in equal proportions. Moreover, we assume that the other parameters are constants. We simulate the evolution of firms' environmental innovation behavior under the three scenarios. The main constants are defined as follows:

$$
\begin{aligned}
& p=20, \mu=30 \%, T=100, \quad \text { inf }=0.05 \text { (random), } x_{a_{1}, 0}^{1}=15, \\
& x_{a_{2}, 0}^{1}=18, \quad x_{a_{3}, 0}^{1}=25, \quad x_{a_{1}, 0}^{2}=18, \quad x_{a_{2}, 0}^{2}=25, \quad x_{a_{3}, 0}^{2}=15, \\
& x_{a_{1}, 0}^{3}=15, \quad x_{a_{2}, 0}^{3}=15, \quad x_{a_{3}, 0}^{3}=25, \varepsilon^{h}=0.1, \text { sens } 1=0.2 \quad(\text { ran- }
\end{aligned}
$$$$
\text { dom), sens } 2=1 \text { (random), inv }=100, w=10, m_{-} \text {step }=5 \text {, }
$$ 


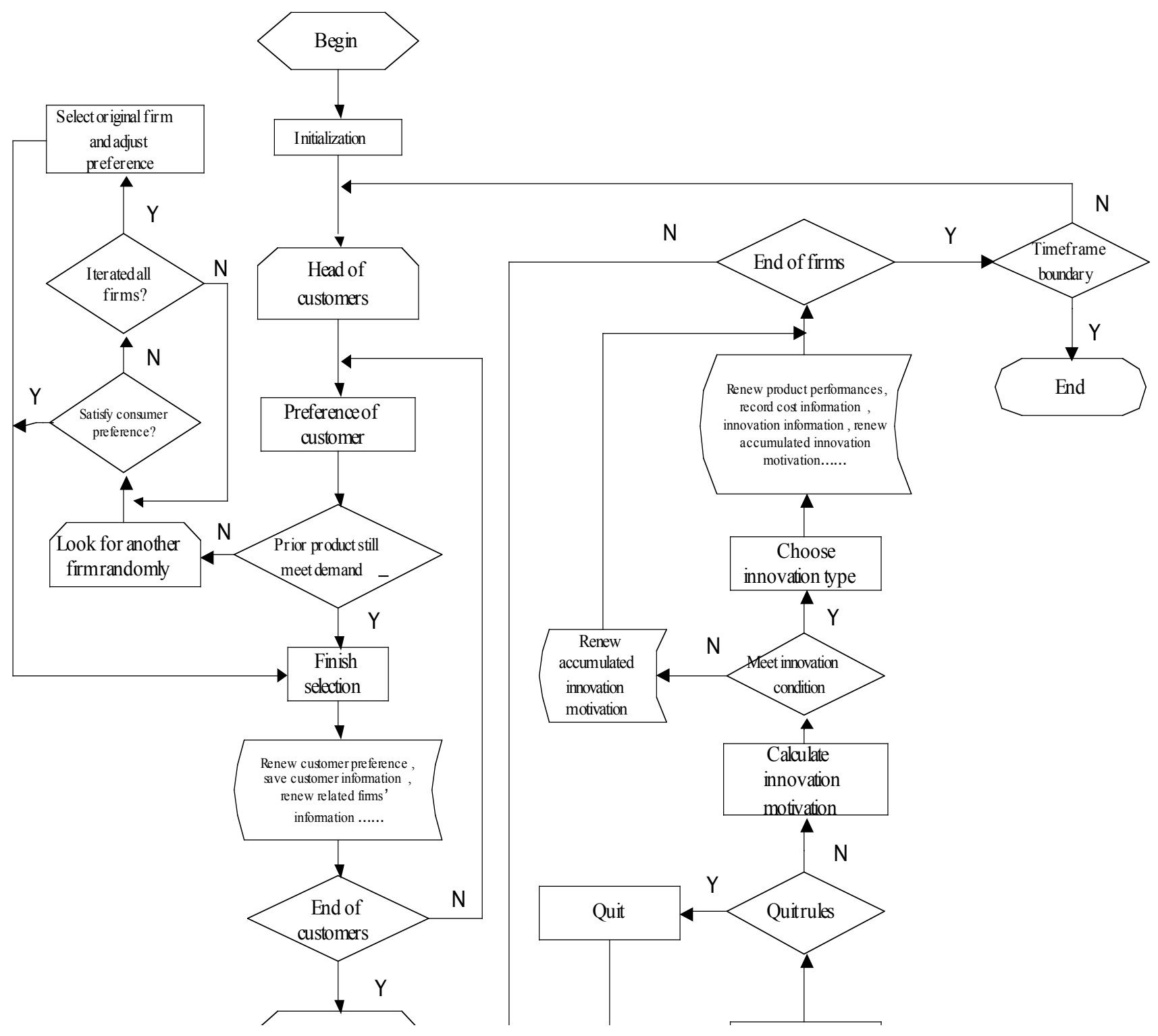

Fig. (2). Operational flow chart of the model.

$m_{-} b a c k^{1}=1, m_{-} b_{a c k}{ }^{2}=1$. Because of the complexity of micro-level heterogeneity and the adaptation of agents, the results are not identical in many of the experiments, even if all of the parameter values are identical. To avoid a onesided conclusion, we perform numerous repetitions of the experiments (more than 30 trials) under each scenario, and only representative results were selected for further analysis.

\subsection{Trend Analysis of Market Share Under Different Levels of Green Demand}

The timeframe that we investigate is 100 time-steps. The proportions of initial green consumers are $10 \%, 30 \%$, and $60 \%$, and we calculate the inverse of the Herfindahl Hirschmann Index to reflect the concentration in each market. The trend results are presented in Fig. (3).

The market share of each firm is identical in the initial stage, and the market concentration is relatively low. After several time-steps, the market concentration varies across scenarios. Specifically, higher green demand leads to higher

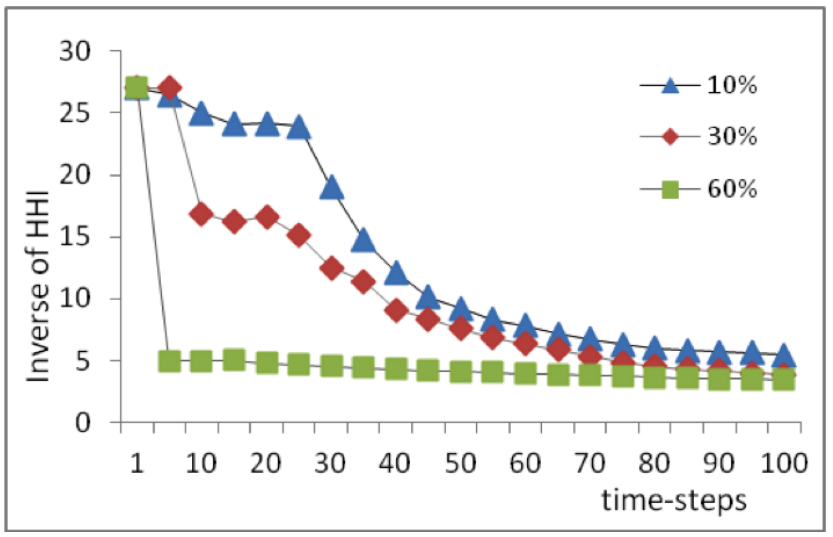

Fig. (3). Evolution of market concentration under different level of green demand.

market concentration, i.e., few firms serve most of the market. Moreover, higher green demand induces the market to concentrate earlier and leads to fiercer competition. Firms therefore must not only improve their product performance 


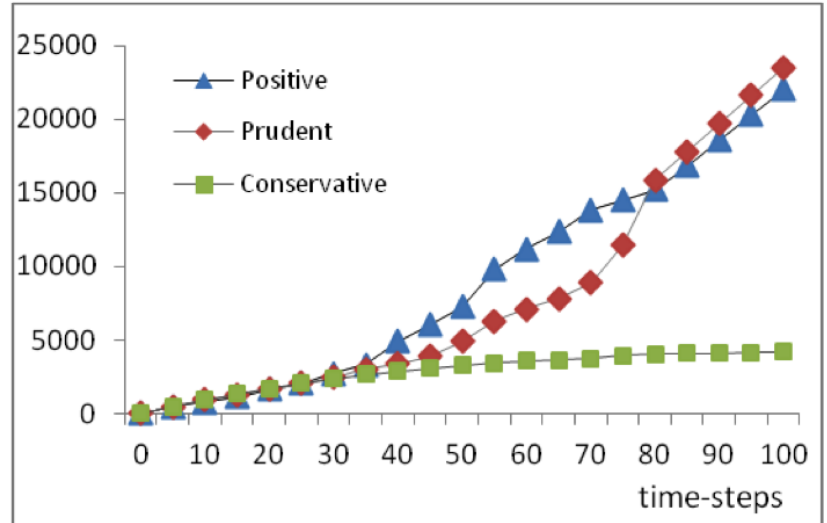

(a) Average profits under 10\% green demand

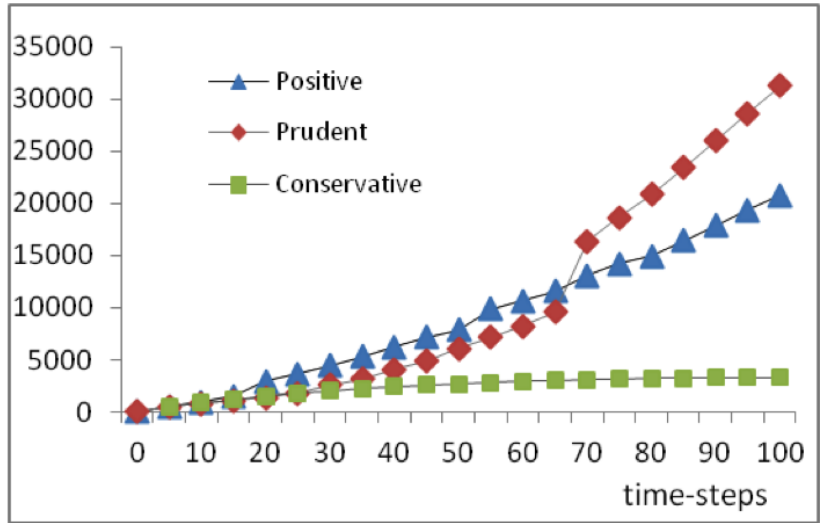

(b) Average profits under 30\% green demand

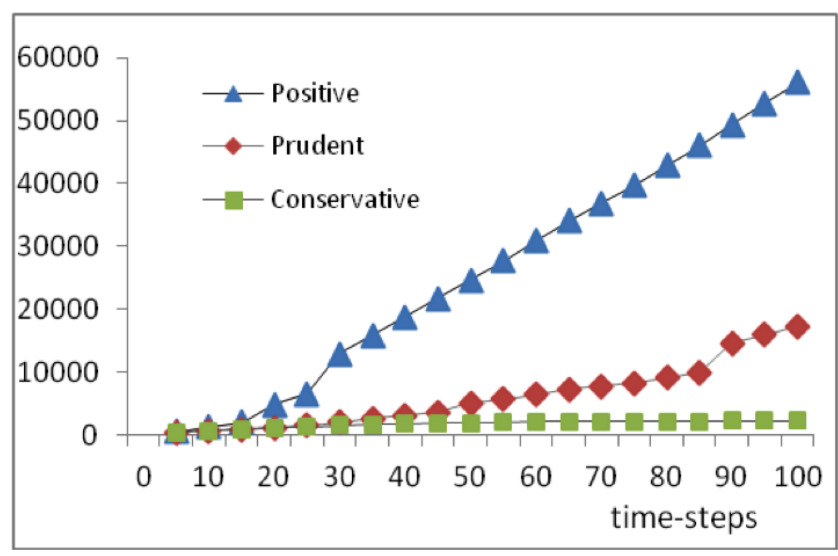

(c) Average profits under 60\% green demand

Fig. (4). Evolution of innovation attitudes and economic performance.

through technical innovation but also seize the opportunity early. Only firms that lead in technology are able to win in the market and remain, whereas firms that consistently follow others are eliminated from the market. The relationship between innovation attitudes and average profits is depicted in Fig. (4).

When green demand is low, the average profits of "positive" firms are lower than those of "prudent" firms. Innovation requires high investment, yet in a market with low green demand, innovative products cannot attract a sufficient number of consumers; hence adopting a "prudent" strategy is sensible to avoid market risk. By contrast, when green demand is high, "positive" firms" average profits are much higher than those of "prudent" and "conservative" firms. As traditional products cannot satisfy most of the market demand, "positive" firms will develop new product to satisfy consumers in advance to obtain a large market share. At this point, revenues from innovation are substantially higher than innovation investments. "Positive" and "prudent" firms improve their product performance through innovation, which is followed by an increasing level of overall consumer demand. Therefore, after several time-steps, "conservative" firms' products can no longer satisfy the growing demand. In Fig. (4a), we can see that the average profits of "conservative" firms are slightly higher than those of "prudent" and "positive" firms but that "conservative" firms' average profits are the lowest among the three types of firms in the long term.

\subsection{Firms' Environmental Innovation Behavior Under Different Scenarios}

The number of firms pursuing traditional innovation or environmental innovation in each time-step under different green demand scenarios is depicted in Fig. (5) (the section between 0 and 1 represents traditional innovation, and the section between 1 and 2 represents environmental innovation).

As green demand increases, firms' innovation frequency increases over time. Further, under the $60 \%$ green demand scenario, more firms decide to adopt environmental innovation as their initial innovation action. Fig. (5a) shows that when the initial green demand level is $10 \%$, most of the firms adopt traditional innovations to improve their production efficiency (and reduce their product price) or product quality. With an increase in green demand, firms engage in environmental innovation for longer periods, as depicted in Figs. (5b) and (5c). Moreover, we can see from Fig. (5d) that green demand is closely related to products' environmental performance. When green demand is high, products' environmental performance is also high. We further calculate the average profits for different firms according to their innovation preferences under different levels of green demand. The results are plotted in Fig. (6).

Under the $10 \%$ green demand scenario, "traditional" firms obtain the highest average profits, while "environmental protection" firms obtain the lowest average profits. 


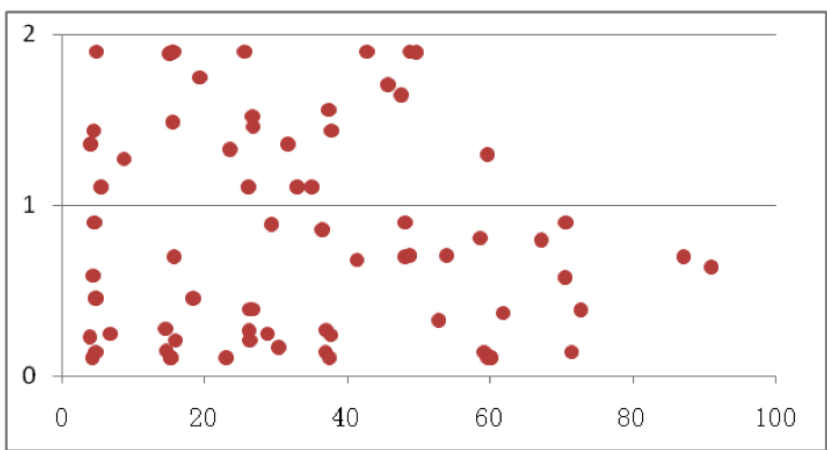

(a) Innovation under $10 \%$ green demand

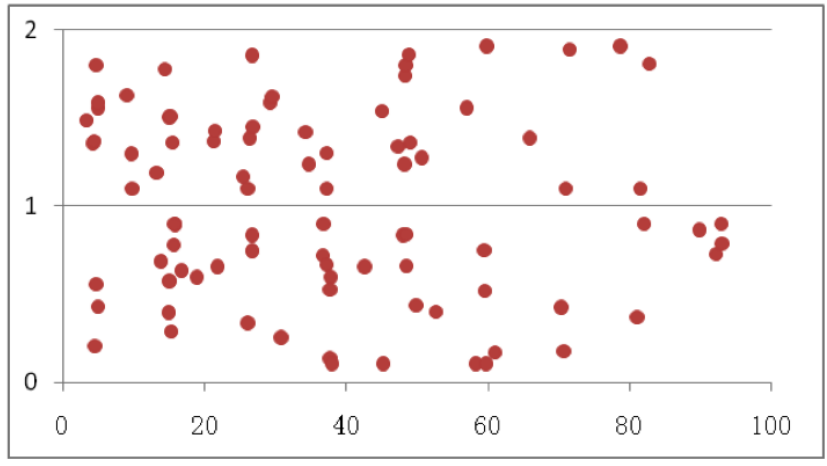

(c) Innovation under 30\% green demand

Fig. (5). Evolution of innovation under different scenarios.

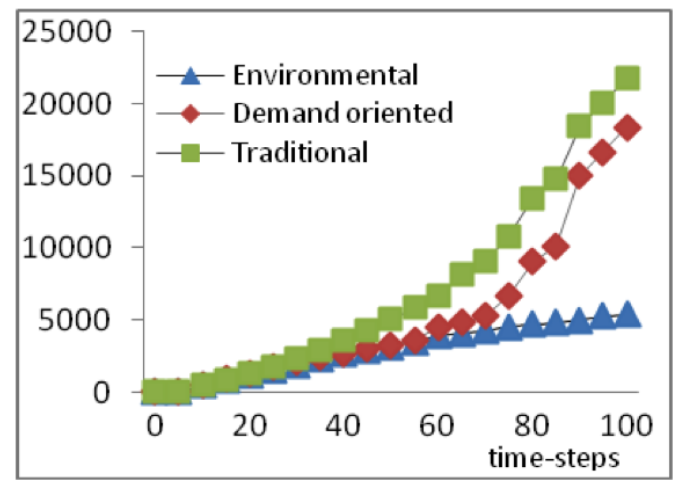

(a) $10 \%$ green demand

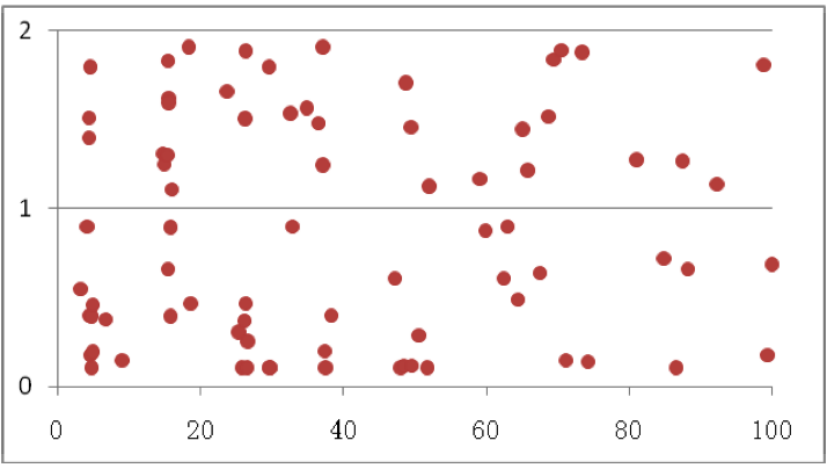

(b) Innovation under 30\% green demand

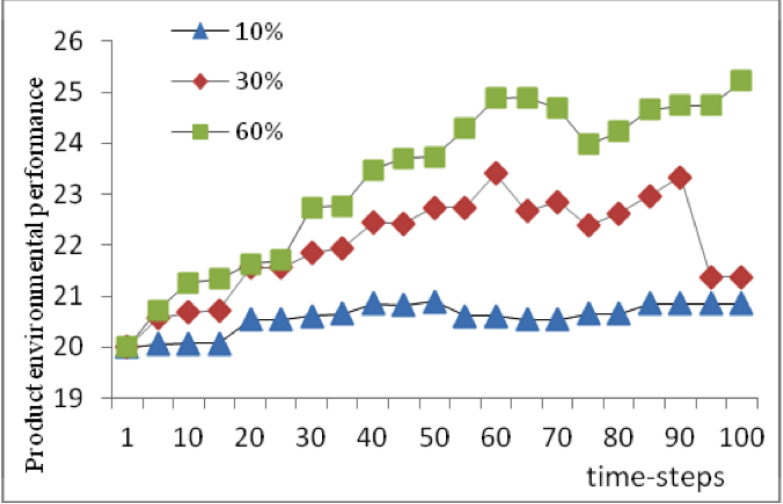

(d) Environmental performance

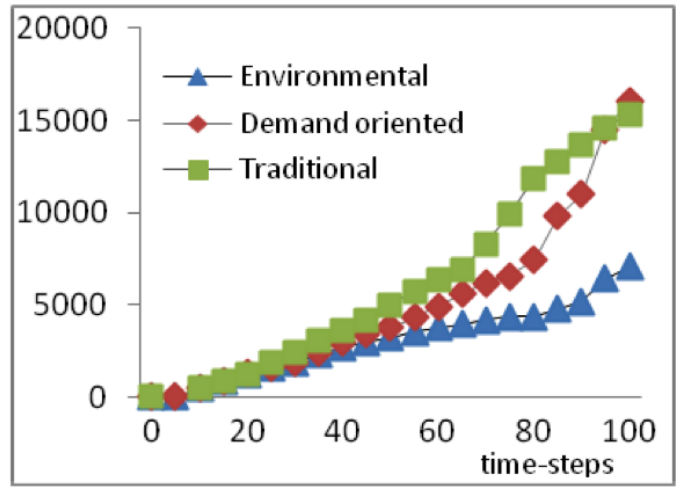

(b) $30 \%$ green demand

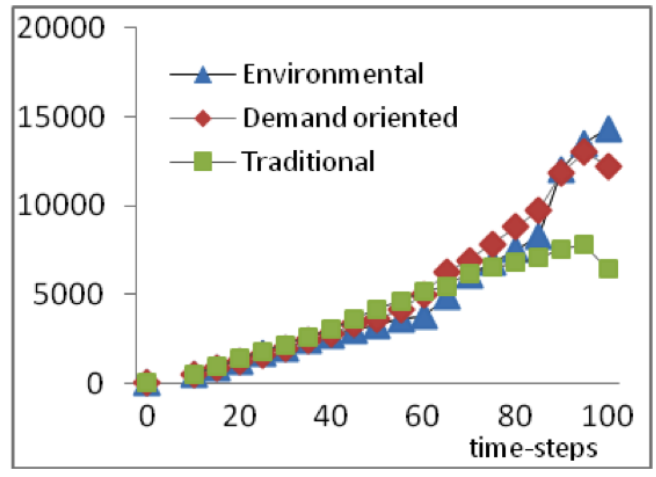

(c) $60 \%$ green demand

Fig. (6). Evolution of firms' average profits under different innovation preferences. 


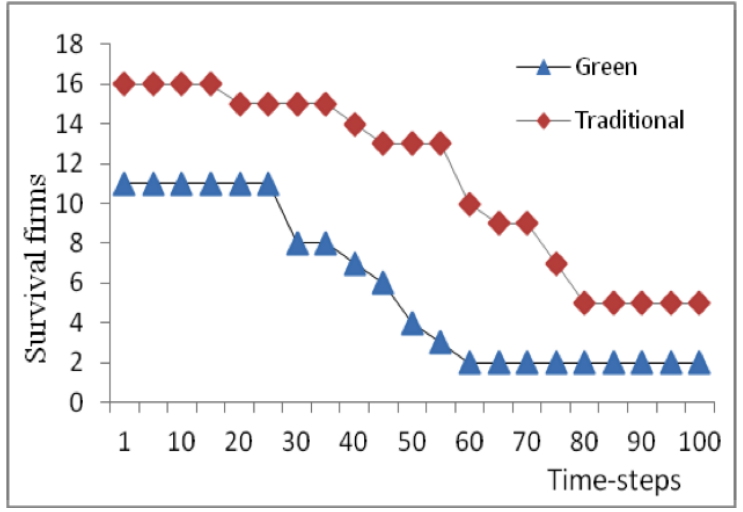

(a) Survival firms under 10\% green demand

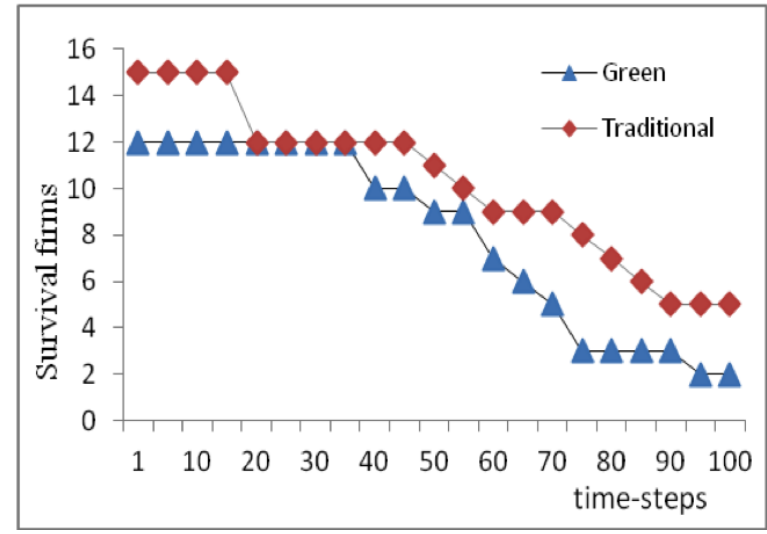

(c) Firm survival under 30\% green demand

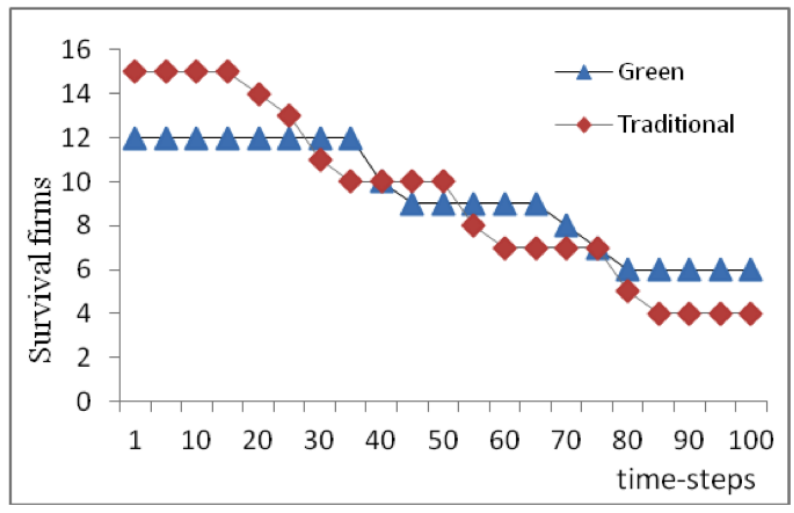

(e) Firm survival under $60 \%$ green demand

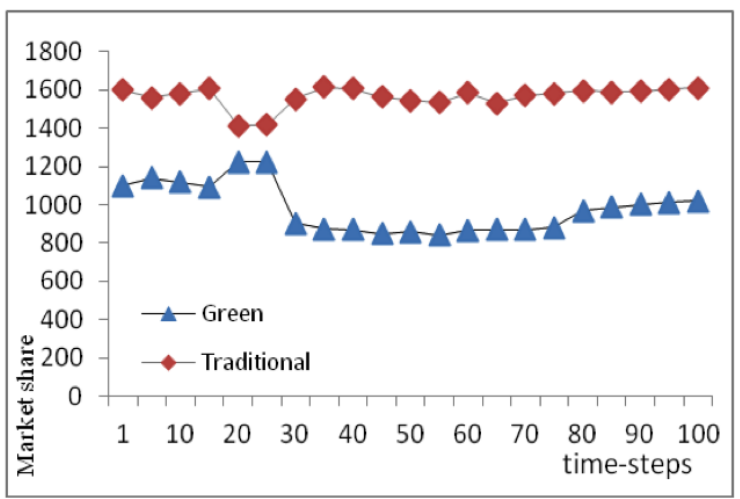

(b) Average market shares under $10 \%$ green demand

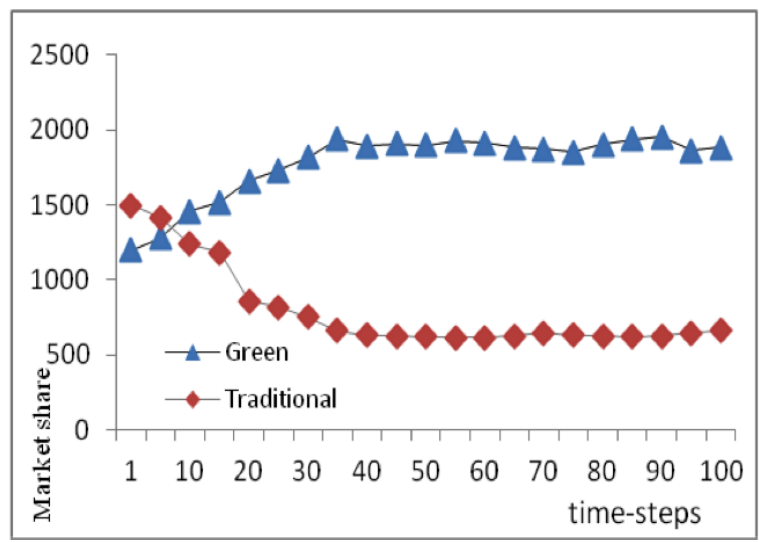

(d) Average market shares under 30\% green demand

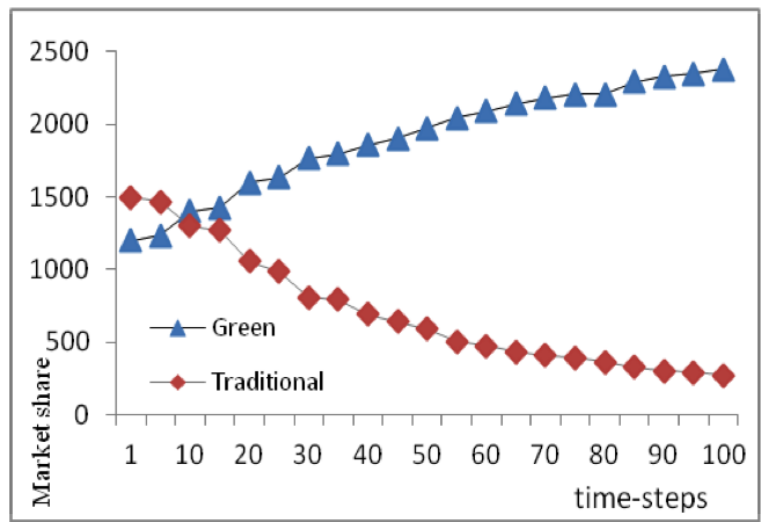

(f) Average market shares under $60 \%$ green demand

Fig. (7). Evolution of firms' environmental behavior and their survival status under different levels of green demand.

When green demand is $30 \%$, "traditional" firms obtain the highest profits before the 95th time-step; however, after 95 time-steps, "demand oriented" firms gradually become the most successful. Moreover, the profits of "environmental protection" firms tend to improve after the 90th time-step, although these firms do not ultimately overtake "traditional" firms in financial performance. Under the $60 \%$ green demand scenario, the average profits of all types of firms are approximately identical before the 85th time-step. However, after the 85th time-step, "traditional" firms rapidly fall behind "demand oriented" and "environmental protection" firms, and after the 95th time-step, "environmental protection" firms ultimately overtake the other types of firms in financial performance and become the market leaders.

\subsection{Relationship Between Firms' Environmental Innova- tion Behavior and their Survival Status}

Firms' environmental innovation behavior is not only affected by their innovation preferences but also determined by the comprehensive effect of various factors, such as firms' financial situation, the market demand, and so on. According to the actual environmental behavioral trajectory over 100 time-steps, we divide all of the firms into two groups: green firms and traditional firms. We define green firms as those that have engaged in environmental innovation at least once and traditional firms as those that have never engaged in environmental innovation. The survival statuses and market shares of the two groups are depicted in Fig. (7). 
When green demand is $10 \%$, more traditional firms survive than green firms, and traditional firms have a higher average market share than green firms. Further, after the 30th time-step, a large number of green firms are eliminated, as depicted in Figs. (7a) and (7b). When green demand is $30 \%$, after the 10th time-step, the average market share of green firms exceeds that of traditional firms; nevertheless, a large number of green firms are eliminated after the 40th timestep, and fewer green firms survive than traditional firms. However, under this scenario, green firms have a much higher average market share than traditional firms, as depicted in Figs. (7c) and (7d). When green demand reaches $60 \%$, after the 20th time-step, many traditional firms are eliminated, and after the 30th time-step, the number of green firms exceeds the number of traditional firms. Although some of the green firms are also eliminated after that point, the number of green firms eventually exceeds that of traditional firms. Furthermore, after the 10th time-step, the market share of green firms gradually increases, while traditional firms' market share gradually diminishes, and ultimately, traditional firms have a much lower market share than green firms, as depicted in Figs. (7e) and (7f). When green demand is sufficiently high, firms that are never interested in pursuing environmental innovation will be eliminated from the market.

\section{CONCLUSION}

This paper applied a computational experimental approach to simulate firm's environmental innovation behavior. We constructed heterogeneous firm agents with different innovation preferences, innovation attitudes, and financial situations and heterogeneous consumer agents with different preferences regarding product price, quality, and environmental performance. We designed the product selection procedure according to consumers' individual preferences and firms' innovation adoption procedure for increasing their products' performance to satisfy consumers' demands. After a certain number of simulated time-steps under various scenarios, we analyzed firms' innovation trajectory and discussed the relationship between green demand and environmental innovation. The experiment revealed that firms' engagement in environmental innovation is closely related to the market demand for green products. When the environmental performance of products is low, substantially increased green demand will rapidly lead to a market monopoly: firms that seize the opportunity to implement environmental product innovations early will rapidly take over the market, whereas later adopters will easily be eliminated from the market after losing a large number of customers. However, when green demand is low, the profits of "environmental protection" firms are much lower than those of "traditional" firms. Thus, to maintain "environmental protection" firms' enthusiasm for innovation, the government should implement policies such as subsidies or incentives that encourage environmental innovation behavior. When green demand reaches a certain level, however, "environmental protection" firms will eventually win in the market.

\section{CONFLICT OF INTEREST}

The authors confirm that this article content has no conflict of interest.

\section{ACKNOWLEDGEMENTS}

This work is supported by the National Natural Science Foundation of China (No.71171099, 71471076, 71411170250), the Doctoral Program Foundation of Institutions of Higher Education of China (No.20123227110011), the Fund of the Ministry of Education of Humanities and Social Sciences (No.14YJAZH025), China Postdoctoral Science Foundation (No.2013M530862, 2014M551525), the Natural Science Foundation of Shandong Province (No.ZR2013GM003), and the Jiangsu Postdoctoral Research Grants Program (No.1302056C). The authors are grateful to the anonymous referee for carefully verifying the details and for providing helpful comments that improved this paper.

\section{REFERENCES}

[1] W. Roel, "Empirical research methods for technology validation: Scaling up to practice," Journal of Systems and Software, vol. 95, pp. 19-31, 2014,

[2] P. Iason, C. Dimitrios, and K. Irene, "Purchase decisions of greek consumers: an empirical study," Procedia Economics and Finance, vol. 9, pp. 456-465, 2014.

[3] L David, P. Alex, A. Lada, A. Sinan, L.B. Albert, B. Devon, C. Nicholas, C. Noshir, F. James, G. Myron, J. Tony, K. Gary, M. Michael, R. Deb, V.A. Marshall, "Computational social science", Science, vol. 323, no. 5915, pp. 721-723, 2009.

[4] D.Y. Kenett, F. Morstatter, H.E. Stanley, and H. Liu, “Discovering social events through online attention", PLOS ONE, vol. 9, no. 7,p. e102001, 2014

[5] Z. Juan, "R\&D for environmental innovation and supportive policy: the implications for new energy automobile industry in China", Energy Procedia, vol. 5, pp. 1003-1007, 2011.

[6] K. Frenken, and A. Faber, “Introduction: Evolutionary methodologies for analyzing environmental innovations and the implications for environmental policy", Technological Forecasting and Social Change, vol. 76, pp. 449-452, 2011.

[7] C. J. Yang, and J. L. Chen, "Accelerating preliminary ecoinnovation design for products that integrates case-based reasoning and TRIZ method", Journal of Cleaner Production, vol. 19, pp. 998-1006, 2011.

[8] B. Zhang, J. Bi, Z.W. Yuan, S. Wang, and J. Ge, "Corporation environmental behavior: a microcosmic perspective of environmental policy analysis. China Population", Resources and Environment, vol. 17, no. 3, pp. 40-44, 2007.

[9] Q. Zhang, and S. Y. Qu, "Research on dynamic game between government and corporation environmental behavior and optimal strategies based on environmental regulation", Forecasting, vol. 32, no. 4, pp. 35-40, 2013.

[10] S. S. Erzurumlu, and Y. O. Erzurumlu, “Development and deployment drivers of clean technology innovations", Journal of High Technology Management Research, vol. 24, pp. 100-108, 2013.

[11] B. Zhang, S. C. Yang, and J. Bi, “Enterprises' willingness to adopt/develop cleaner production technologies: an empirical study in Changshu, China", Journal of Cleaner Production, vol. 40, pp. 62-70, 2013.

[12] F. Y. Lu, "Evolutionary game analysis on environmental pollution problem”, System Engineering-Theory \& Practice, vol. 9, pp. 148152, 2007.

[13] W. Paul, C. Tommaso, and B. Chris, "Consumer heterogeneity and the development of environmentally friendly technologies", Techno-logical Forecasting \& Social Change, vol. 76, pp. 533-551, 2009.

[14] S. Youn, M. G. Yang, P. Hong, and K. Park, "Strategic supply chain partnership, environmental supply chain management practices, and performance outcomes: an empirical study of Korean firms", Journal of Cleaner Production, vol. 56, pp. 121-130, 2013.

[15] Y. Liu, and H. Ye, “The dynamic study on firm's environmental behavior and influencing factors:an adaptive agent-based modeling approach," Journal of Cleaner Production, vol. 37, pp. 278-287, 2012 . 
[16] Y. Liu, "Investigating external environmental pressure on firms and their behavior in Yangtze River Delta of China", Journal of Cleaner Production, vol. 17, pp. 1480-1486, 2009.

[17] M. L. Tseng, R. Wang, A. S. Chiu, G. Yong, and Y. H. Lin, "Improving performance of green innovation practices under uncertainty", Journal of Cleaner Production, vol. 40, pp. 71-82, 2013.

[18] K. B. Monroe, "Pricing: making profitable decisions," New York: MaGraw-Hill, 1990.

[19] Z. D. Wen, and T. M. Chen, "The exploration of green innovation organization in Taiwan", Management Forum of Taiwan University, vol. 8, no. 2, pp. 99-124, 1998.

[20] C. Bekiroglu, O. Erdil, and L. Alpkans, "Variables perceived by managers as antecedents that lead firms to environmental management: an empirical research in the Turkish construction sector", Procedia-Social and Behavioral Sciences, vol. 24, pp. 101-122, 2011.

[21] W. Paul, C. Tommaso, and B. Chris, "Environmental impact, quality, and price: Consumer trade-offs and the development of environmentally friendly technologies", Technological Forecasting \& Social Change, vol. 76, pp. 552-566, 2009.

[22] H. George, and S. Anastasios, "Can capital markets respond to environmental policy of firms? Evidence from Greece", Ecological Economics, vol. 63, pp. 578-587, 2007.
[23] E. Horvathova, "Does environmental performance affect financial performance? A meta-analysis", Ecological Economics, vol. 70, no. 1, pp. $52-59,2010$

[24] R. Cowe, and S. Williams, "Who are the ethical consumers? London," UK: The Co-operative Bank, 2000.

[25] R.J. Lin, K.H. Tan, Y. Geng, “Market demand, green product innovation, and firm performance: evidence from Vietnam motorcycle industry", Journal of Cleaner Production, vol. 40, pp. 101107, 2013.

[26] H. Eva, "The impact of environmental performance on firm performance: Short-term costs and long-term benefits? Ecological Economics, vol. 84, pp. 91-97, 2013.

[27] S. C. Xu, Z. X. He, R. Y. Long, “Comparative research on environmental policy instruments: Enterprise emission abatement perspective", System Engineering-Theory \& Practice, vol. 32, no. 11, pp. 2351-2362, 2012

[28] M A. Ilker, "The impact of green product innovation on firm performance and competitive capability: the moderating role of managerial environmental concern", Procedia-Social and Behavioral Sciences, vol. 62, pp. 854-864, 2012

(C) Zhao et al.; Licensee Bentham Open.

This is an open access article licensed under the terms of the Creative Commons Attribution Non-Commercial License (http://creativecommons.org/licenses/by-nc/3.0/) which permits unrestricted, non-commercial use, distribution and reproduction in any medium, provided the work is properly cited. 